\title{
Klinefelter's syndrome associated with systemic sclerosis
}

\author{
D. J. O'DONOGHUE* \\ B.Sc., M.B., Ch.B. \\ Department of Rheumatology, Manchester Royal Infirmary
}

\begin{abstract}
Summary
A case of systemic sclerosis is reported in a 41-yearold male with Klinefelter's syndrome. The signifcance of this association to the aetiology and pathogenesis of systemic sclerosis is discussed.
\end{abstract}

\section{Introduction}

The association of Klinefelter's syndrome (chromosomal complement $47, \mathrm{XXY}$ ) with systemic lupus erythematosus is well recognized (Masi and Kaslow, 1978). Tsung and Heckman (1974) report the occurrence of localized scleroderma, Raynaud's phenomenon, Sjögrens syndrome, Osler-WeberRendu disease and malignant lymphoma in a 47 , XXY male. The case discussed here describes the association of Klinefelter's syndrome and systemic sclerosis.

\section{Case report}

A 41-year-old male, who had Raynaud's phenomenon for 12 years, presented with a one year history of skin thickening with discoloration and tightness of his hands, face, chest and thighs. He had also noticed increasing exertional dyspnoea, weakness and stiffness of his arms and neck, and had lost weight. His marriage was infertile.

He exhibited the classical features of scleroderma with extensive areas of thickened, tight, shiny and tethered skin. Pigmentation, depigmentation and telangiectasia were also present. He had microstomia and clawed hands. In addition, his body habitus was typical of Klinefelter's syndrome (height $179.6 \mathrm{~cm}$ : arm span $192.6 \mathrm{~cm}$ ). He was obese, had infantile gonads, gynaecomastia and decreased body hair with a female escutcheon. Auscultation of the lungs revealed fine basal end-inspiratory crackles. There was mild neck flexor and shoulder girdle weakness.

His haemoglobin was $11 \cdot 2 \mathrm{~g} / \mathrm{dl}$ with normal

\footnotetext{
* Present Address: Department of Medicine, Hope Hospital, Eccles Old Road, Salford, Greater Manchester.
}

erythrocyte indices and a normal differential white cell count. The erythrocyte sedimentation rate was 41 $\mathrm{mm}$ in the first hour (Westergen). The serum urea, 12 channel biochemical profile, creatinine clearance and tests of thyroid, liver and small bowel function were within normal limits.

Immunological evaluation revealed an IgG antinuclear factor (1/300 titre) with a speckled pattern. Immunoglobulin levels and serum protein electrophoresis were normal, as were the $\mathrm{C}_{3}, \mathrm{C}_{4}, \mathrm{CH}_{50}$ and Factor B components of complement. An assay for CIq binding was in the normal range. Tests for sheep red cell agglutination, latex fixation and antibodies to deoxyribonucleic acid, extractable nuclear antigen, smooth muscle, mitochondria and reticulin were negative. Cryoglobulins, cold agglutinins and lupus erythematosus cells were not detected. A Wassermann reaction and VDRL test were negative.

Profuse exfoliation of atypical alveolar macrophages was found on cytological examination of the sputum and pulmonary function tests showed a restrictive ventilatory impairment.

Radiological investigations revealed a normal thoracic inlet, plate atelectasis in the left lower lung zone and juxta-articular osteoporosis at the metacarpophalangeal joints. A gastrointestinal tract barium series was normal apart from disclosing a widenecked diverticulum on the medial aspect of the ascending colon.

Buccal smear examination revealed sex chromatin in 9\% of cells and Klinefelter's syndrome was confirmed by karyotype analysis with chromosome banding showing a 47, XXY pattern.

\section{Discussion}

This is the first report of systemic sclerosis developing in a patient with Klinefelter's syndrome, although scleroderma without post-mortem evidence of systemic sclerosis in a patient with Klinefelter's syndrome and a malignant lymphoma has been described (Tsung and Heckman, 1974). Although the 
possibility that this association is fortuitous cannot be excluded, both systemic sclerosis (annual incidence of 2.7 new cases per million population (Medsger and Masi, 1971)) and Klinefelter's syndrome (annual incidence of 0.93 per 1,000 live male births (Hook and Hamerton, 1977)) are sufficiently uncommon for this to be unlikely. The female preponderance of $3: 1$ in systemic sclerosis (Kurland et al., 1969) suggests sex-related host factors in the increased susceptibility of females or, conversely, protection of males. Such factors may explain an association of systemic sclerosis and an XXY chromosome genotype.

It is of interest that a female preponderance and association with Klinefelter's syndrome occurs in systemic lupus erythematosus (Masi and Kaslow, 1978). Possible explanations include somatic mutation on X chromosomes, increased fetal wastage of genetically normal males predisposed to systemic lupus erythematosus (or systemic sclerosis), infectious agent susceptibility or altered immune responsiveness related to genetic or hormonal status, and direct hormonal effects on the tissues. In addition to the mandatory chromosomal abnormality in Klinefelter's syndrome there are a host of hormonal and biochemical abnormalities (Paulsen et al., 1968).

\section{Acknowledgments}

The author wishes to thank Dr P. J. L. Holt for permission to publish the case, Dr R. Trapp and Dr G. Jones for helpful criticism and Miss N. Magennis for her secretarial work.

\section{References}

HOOK, E.B. \& HAMERToN, J.L. (1977) The frequency of chromosome abnormalities detected in consecutive newborn studies. In: Population Cytogenetics: Studies in Humans (Ed by Hook, E.B. \& Porter, I.H.) p. 63. Academic Press, New York.

KuRland, L.T., HAUSER, W.A., FERGUSON, R.H. \& Holley, K.E. (1969) Epidemiologic features of diffuse connective tissue disorers in Rochester, Minnesota, 1951-1967 with special reference to systemic lupus erythematosus. Proceedings of Staff Meetings of the Mayo Clinic, 44, 649.

MASI, A.T. \& KASLOW, R.A. (1978) Sex effects in systemic lupus erythematosus. A clue to pathogenesis. Arthritis and Rheumatism, 21, 480.

MEDSGER, T.A., JR \& MASI, A.T. (1971) Epidemiology of systemic sclerosis (scleroderma). Annals of Internal medicine, 74, 714.

Paulsen, C.A., Gordon, D.L., Carpenter, R.W., Gandy, H.M î \& DRUCKER, W.D. (1968) Klinefelter's syndrome and its variants: जV A hormonal and chromosomal study. Recent Progress in Hormone Research, 24, 321.

TsuNG, S.H. \& HeCKMan, M.G. (1974) Klinefelter's syndrome, immunological disorders and malignant neoplasm. Archives of Pathology, 98, 351. 